\title{
GEOMORFOLOGIA ESTRUTURAL DO GRÁBEN DO RIO MAMANGUAPE E ADJACÊNCIAS - ESTADO DA PARAÍBA, BRASIL
}

\author{
STRUCTURAL GEOMORPHOLOGY OF MAMANGUAPE RIVER GRABEN \\ AND ADJACENT AREAS - STATE OF PARAIBA, BRAZIL
}
GEOMORFOLOGÍA ESTRUCTURAL DEL GRABEN DEL RÍO MAMANGUAPE
Y ADYACENCIAS - ESTADO DE PARAÍBA, BRASIL
Max Furrier - Universidade Federal da Paraíba - João Pessoa - Paraíba - Brasil
max.furrier@hotmail.com

Wesley Ramos Nóbrega - Universidade Federal da Paraíba - João Pessoa - Paraíba - Brasil

wesjppb@gmail.com

Alexandre dos Santos Souza - Universidade Federal da Paraíba - João Pessoa - Paraíba - Brasil

alesougeo@hotmail.com

\section{Resumo}

Este artigo baseia-se na caracterização morfoestrutural do gráben do rio Mamanguape, localizado ao norte da borda oriental do estado da Paraíba, no Nordeste do Brasil. Através de mapeamento de detalhe, tem-se como objetivo gerar informações quantitativas e morfológicas condicionadas pelo atual arcabouço estrutural do gráben do rio Mamanguape e suas adjacências. Para a elaboração dos produtos cartográficos, foram digitalizadas e vetorizadas, em todo 0 seu conteúdo, três cartas topográficas na escala 1:25.000, com equidistância das curvas de nível de $10 \mathrm{~m}$, que abrange toda a área em estudo. A partir dos produtos cartográficos gerados, foi possível observar e quantificar aspectos morfológicos e morfoestruturais na área como: diferenças altimétricas discrepantes entre seus setores norte e sul, que percorre toda a adjacência do gráben, escarpas abruptas com declividades mais acentuadas no setor norte, vertentes em ombreiras ou shoulders, padrões assimétricos das redes de drenagem e orientações anômalas e inflexões bruscas de vários canais fluviais erecuos acelerados de cabeceiras de drenagem. Essas características atestam para um controle morfoestrutural da área, haja vista que apenas o fator climático impossibilitaria o padrão morfológico encontrado.

Palavras-chave: gráben do rio Mamanguape, Formação Barreiras, tabuleiros litorâneos.

\section{Abstract}

This present work is based on the morphostructural characterization of Mamanguape River graben, located in the north portion of the eastern border of the State of Paraíba, northeast of Brazil. By using detailed mapping, we aim to produce quantitative and morphological information, conditioned by the present structural framework of Mamanguape River graben and its adjacencies. For the elaboration of the cartographic products, three topographic maps, with scale 1:25.000 and $10 \mathrm{~m}$ equidistance interval of the contour-lines, which covers the whole area at issue, were entirely digitalized and vectorized. With this scale, it was possible to make an inedited detailed mapping of Mamanguape River graben and its adjacencies. By using the cartographical products generated, it was possible to observe and quantify the morphological and morphostructural aspects in the area, such as: discrepant altimetricdifferencies between its north and south sectors, that run along the adjacency of the graben, abrupt slopes with more marked declivity on the north sector, hogbacks on shoulders, drainage network assimetric patterns and anomalous orientations and abrupt inflexions of various fluvial canals and accelerated backings of drainage headwaters. These characteristics point to the existence of a morphostructural control in the area, once only the climatic factor would make it impossible the formation of the morphological pattern found on it.

Key words: Mamanguape river graben, Barreiras Formation, coastal tablelands. 


\section{Resumen}

Este trabajo se basa en la caracterización morfoestructural del graben del río Mamanguape, ubicado al norte del borde oriental del estado de Paraíba, noreste del Brasil. El objetivo es, a través de la cartografía detallada, generar informaciónes cuantitativas y morfológicas acondicionadas por el actual marco estructural del graben del río Mamanguape y sus alrededores. Para la preparación de los productos cartográficos fueron escaneados y vectorizados, en todos sus contenidos, tres planchas topográficas en la escala 1:25.000, con curvas de nivel de intervalo de $10 \mathrm{~m}$, cubriendo toda el área de estudio. Con esa escala, hecho posible un mapeo de detalle sin precedentes del graben del río Mamanguape y adyacencias. A partir de los productos cartográficos generados, fue posible observar y cuantificar los aspectos morfológicos y morfoestructurales de la zona como las diferencias altimétricas dispares entre sus sectores norte y sur, que se extiende junto a las adyacencias del graben, acantilados escarpados con pendientes más pronunciadas en el sector norte, pendientes en hombros o shoulders, los patrones asimétricos de las redes de drenaje y directrices anómalos e inflexiones bruscas de diversos canales de los ríos y retiros acelerados de cabecera de drenaje. Estas características atestiguan para el control morfoestructural de la zona, teniendo en cuenta que sólo el factor climático impide el patrón morfológico encontrado.

Palabras clave: graben del río Mamanguape, Formación Barreiras, mesetas costeras.

\section{Introdução}

Este texto tem o objetivo de apresentar as características morfoestruturais do gráben do rio Mamanguape e adjacências e sua conspícua influência no relevo atual da área. A região corresponde às cartas topográficas de Itapororoca, Rio Tinto e Barra de Mamanguape, todas na escala 1.25.000, que seguem o sentido W-E em direção ao Oceano Atlântico, formando um complexo geomorfológico de estruturas distintas no relevo, na composição do terreno, na hidrografia e nos efeitos provocados pela ação tectônica regional (Furrier, Araújo e Meneses, 2006b).

A caracterização morfoestrutural está atrelada ao forte controle litológico estrutural presente no Terreno Alto Pajeú (TAP) de idade Neoproterozoica, que forma o embasamento de toda a área de estudo, sendo desenvolvidos sobre ele, na porção leste, os Tabuleiros Litorâneos esculpidos, principalmente sobre a Formação Barreiras de idade Miocênica (Brito Neves et al., 2004; Furrier, Araújo e Meneses, 2006b).

Esse terreno (TAP) foi afetado por movimentações no Cenozoico que reativou antigas linhas de falhas do Proterozoico, dando origem ao gráben do rio Mamanguape que se apresenta perpendicular à linha de costa atual (Brito Neves et al., 2004). O TAP e os terrenos limítrofes são afetados por linhas de falhas reativadas do embasamento que foram preenchidas, em muitos casos, pelos cursos d'água regionais. Dentre esses rios, está o Mamanguape, que se apresenta alinhado a um sistema de falhas normais moderno de sentido (WSW-ESE) (Brito Neves et al., 2008). 
Área de estudo

A área de estudo compreende uma faixa emersa de aproximadamente $42 \mathrm{~km}$ de extensão (E-W) por $14 \mathrm{~km}$ de largura (N-S), perfazendo uma área de $588 \mathrm{~km}^{2}$. Todo o compartimento está inserido na microrregião do litoral norte paraibano, sendo o rio Mamanguape a drenagem de maior expressão, formando no seu baixo curso um extenso manguezal que desemboca no Oceano Atlântico (Figura 1). O clima é do tipo Tropical Úmido com verão seco, o período mais chuvoso ocorre no outono, tendo início em fevereiro e término em outubro, com precipitação média anual de aproximadamente $1.800 \mathrm{~mm}$ (CPRM, 2005).

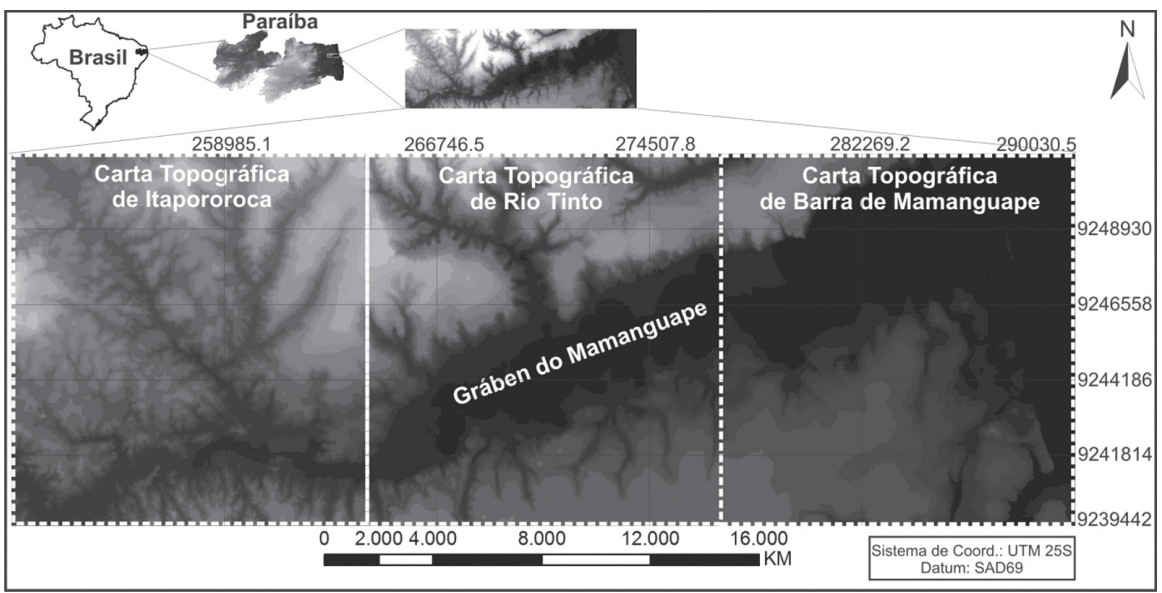

Figura 1- Localização da área de estudo através do Modelo Numérico do Terreno (MNT), identificando as três cartas topográficas utilizadas nesse trabalho.

\section{Contexto geológico e geomorfológico}

De acordo com o mapa geológico do estado da Paraíba (Santos, Ferreira e Silva Júnior, 2002), a região que compreende a área de estudo (Figura 2) é constituída por um compartimento litótopo composto por feições distintas, presentes no embasamento neoproterozoico do terreno Alto Pajeú (TAP), que engloba parte da província da Borborema e avança por baixo da Formação Barreiras, da Bacia Sedimentar Paraíba e dos depósitos quaternários na área. 
O embasamento proterozoico que forma o TAP abrange as três cartas topográficas em estudo, mas sua exposição é majoritária apenas no setor oeste da área (Figura 2).

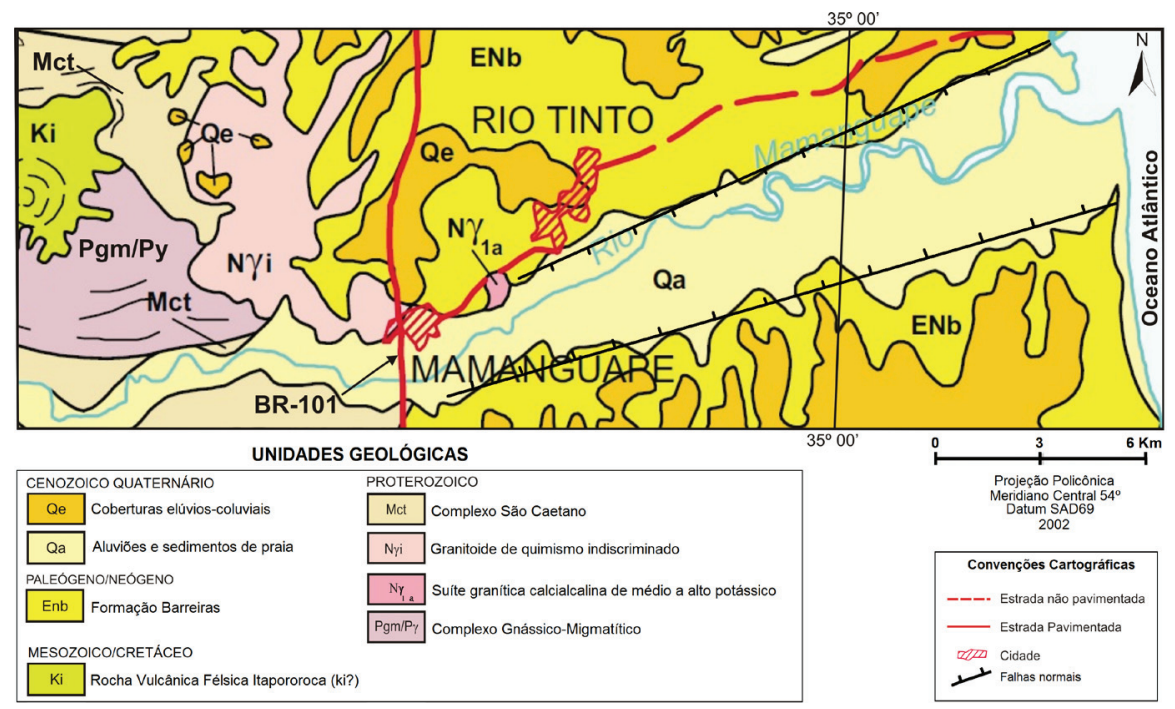

Figura 2- Mapa geológico do estado da Paraíba (modificado de Santos, Ferreira e Silva Júnior, 2002).

O setor centro-leste é constituído por sedimentos arenoargilosos mal consolidados, depositados por sistemas fluviais entrelaçados que dão origem à Formação Barreiras (ENb) e a depósitos quaternários, principalmente os confinados pelo gráben.

No mapa geológico da área de estudo (Figura 2), apresenta-se com distinção a passagem do domínio da Formação Barreiras para o embasamento cristalino localizado a oeste no médio curso do rio Mamanguape, onde é cortado, perpendicularmente, pela BR-101 (Figura 2), da qual se podem avistar exposições de rochas do embasamento cristalino face a face, em mesma cota, com os depósitos sedimentares da Formação Barreiras (Brito Neves et al., 2004). Os depósitos sedimentares da Bacia Sedimentar da Paraíba se encontram a leste da BR-101, abaixo da Formação Barreiras e não afloram na área de estudo.

Esses autores afirmam que, no bloco alto da falha de Mamanguape, apresentam-se as raras exposições do embasamento pré-cambriano, aflo- 
rando em suas vertentes rochas de natureza metagrauváquicas do TAP e um conjunto de rochas graníticas (Brito Neves et al., 2008).

Toda a região está situada entre os lineamentos Patos e Pernambuco, na megaestruturada Zona Transversal, onde se insere o TAP, cujo arcabouço é composto por unidades gnáissicas paleoproterozoicas, metaplutônicas, metavulcanos sedimentares e granitoides, que estão arranjadas entre zonas de cisalhamento transcorrentes associadas ao evento Brasiliano (Santos, Nutman e Brito Neves, 2004).

De acordo com esse mapa geológico do estado da Paraíba, são encontradas, na região estudada, rochas do complexo gnássico-migmatito (Pgm/p $\gamma$ - retrabalhadas no meso e neoproterozoico); vulcânica félsica Itapororoca (Ki - sem dados geocronológicos, sendo atribuída uma idade cretácea por correlação com o vulcanismo da Bacia do Cabo); granitoide de quimismo indiscriminado (N $\gamma \mathrm{i})$; suíte granítica calcialcalina $\left(\mathrm{N} \gamma_{1} \mathrm{a}\right)$; Formação Barreiras (ENb), que apresenta estratificações tabulares/planares de forte ângulo, indicando alta descarga de um sistema fluvial em canais confinados que migram formando as barras; coberturas elúvio-coluviais (Qe); aluviões (Qa) - representados pelos aluviões do rio Mamanguape.

O gráben do rio Mamanguape encontra-se condicionado às zonas de cisalhamentos detalhadas nos trabalhos de Brito Neves et al. (2004; 2008). Dessas falhas, destaca-se a zona de caráter sinistral de Mulungu-Violeta (SW-NE), Mari Barro-Branco ou do rio Gurinhenzinho ao sul, e o trecho norte do lineamento Galante-Guarabira (Brito Neves et al., 2004).

Segundo esses autores, a "tectônica distensional" ocorrida na área, após o arqueamento pós-Cretáceo Superior, surgiu em razão das antigas zonas de falhas pré-cambrianas (Figura 3), apresentadas como cisalhamento simples e de transpressão, do final do Neoproterozoico ao início do Cambriano, que estiveram ativas durante a cratonização da Província Borborema.

O gráben do rio Mamanguape, ainda segundo os autores, apresenta um preenchimento sedimentar descontínuo, em virtude da ação do ciclo erosivo recente, constituído, sobretudo, por depósitos rudáceos, conglomerados, lamitosseixosos a arenosos e arenitos relacionados provavelmente a sistemas de leques aluviais e planícies de rios entrelaçados.

Sendo assim, a geomorfologia se diferencia radicalmente em razão do substrato presente em cada área, além de os rios estarem entalhando, de forma conspícua, vales localizados, sobretudo em áreas cujo compar- 
timento é excepcionalmente sedimentar. Além disso, os tributários do rio Mamanguape, inseridos em zona de ambiente cristalino, apresentam-se tectonicamente encaixados, considerando que não possuem competência para produzir os níveis de declividade identificados em seus cursos, conforme também comentam Brito Neves et al. (2008).

No compartimento litótopo, observa-se uma intensa modelagem do relevo, exercida pelos cursos de água atuais, muitos deles condicionados às falhas, que propiciam a sua esculturação morfológica. Segundo Penteado (1974), uma das características mais importantes dos relevos desenvolvidos sobre rochas areníticas são rios longos e retilíneos, acompanhando o padrão de diáclases e falhamentos. Essa retiliniedade também pode ocorrer em cursos de água incipientes sobre o embasamento cristalino quando o volume de água do rio, por si só, não possui energia para desenvolver seu próprio padrão.

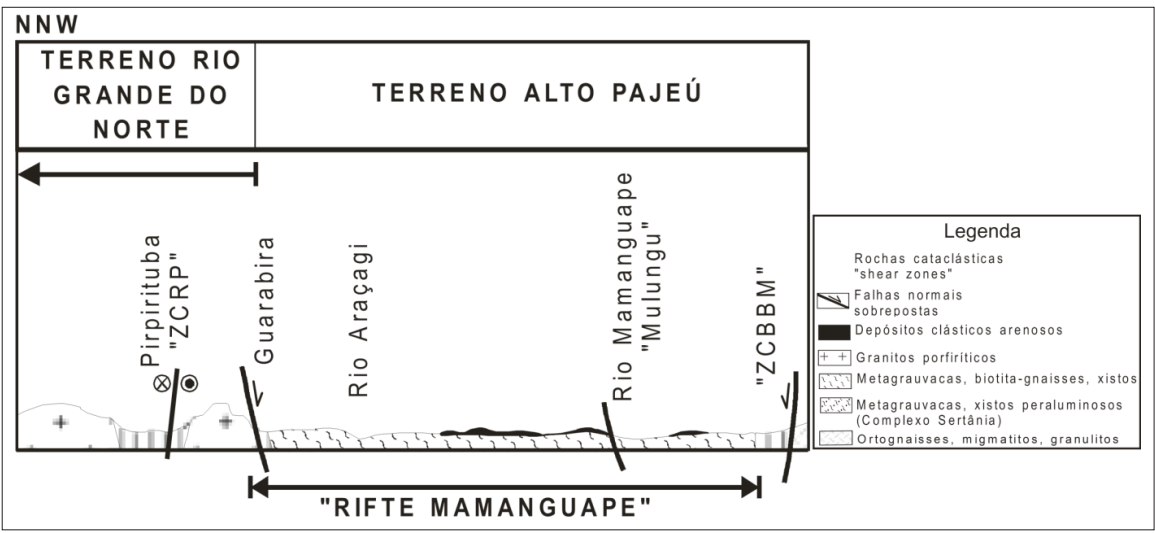

Figura 3 - Recorte da seção geológica esquemática do Sistema Tafrogênico Terciário do Saliente Oriental Nordestino na Paraíba (modificado de Brito Neves et al., 2004).

Ao longo de toda a área de exposição da Formação Barreiras, nos setores norte e sul, constata-se um comportamento de um teclado de piano com horsts e grábens se alternando e, com setores soerguidos e rebaixados, alternadamente, separados pelo principal rio perpendicular à linha da costa, o rio Mamanguape (Furrier, Araújo e Meneses, 2006b). Essa constatação evidente pode-se aplicar a praticamente toda a Borda Oriental do estado da Paraíba, pois são fortes os indícios estruturais relacionados às reativações tectônicas cenozoicas. 
Para Furrier, Araújo e Meneses (2006a), essas áreas são caracterizadas por soerguimentos distintos e basculamentos nos diferentes níveis dos entalhes fluviais e no padrão assimétrico de muitas redes de drenagem. $\mathrm{O}$ arcabouço estrutural também influenciou fortemente o padrão dessas redes de drenagem local e, consequentemente, a disposição dos tabuleiros.

A área mais elevada, localizada na porção norte do gráben, representa o alto estrutural de Mamanguape (Feitosa, Feitosa e Lira, 2002), que teria servido de barreira ao avanço da sedimentação clástica continental precedente do sul, sendo considerado, portanto, como limite norte da Formação Beberibe e dos carbonatos da Formação Gramame, pertencentes à Bacia Sedimentar Paraíba.

\section{Materiais e métodos}

Este trabalho está fundamentado na elaboração de produtos cartográficos digitais, desenvolvidos a partir da vetorização de três cartas topográficas na escala de 1:25.000, com equidistância entre as curvas de nível de $10 \mathrm{~m}$. Essa vetorização, estritamente baseada no conteúdo das cartas topográficas, possibilita um nível de detalhe e de representação da realidade do relevo inédito para a área.

As cartas utilizadas foram Itapororoca (SB.25-Y-A-V-4-NO), Rio Tinto (SB.25-Y-C-III-3-NE) e Barra de Mamanguape (SB.25-Y-A-VI-3-NO), para a elaboração das cartas hipsométrica, clinográfica (Figuras 4b e 4c) e do Modelo Digital de Elevação (MDE) em 3D (Figura 5).

Para a elaboração da carta clinográfica, foram adotadas as classes de declividade propostas por Herz e De Biase (1989). As definições das classes de declividades usadas neste trabalho estão unidas às classes e aos limites utilizados internacionalmente, bem como a trabalhos desenvolvidos por institutos de pesquisa nacionais e a leis vigentes no Brasil.

As cartas topográficas foram digitalizadas em formato JPEG, que permite sua importação para o software Draft Sight, com o intuito de realizar a vetorização dos elementos cartográficos necessários para serem exportados para o software SPRING 5.1.7, possibilitando a confecção das cartas temáticas (hipsométrica e clinográfica) e do MDE 3D, que foi gerado a partir da imagem em nível cinza interpolada a partir das curvas de nível e dos pontos cotados vetorizados. 


\section{Resultados}

A partir das análises e interpretações dos produtos cartográficos gerados através das cartas topográficas na escala 1:25.000, com equidistância das curvas de nível de $10 \mathrm{~m}$, percebe-se com uma precisão consubstancial que as diferenças altimétricas de declividade das vertentes e da rugosidade do relevo não podem ser explicadas única e exclusivamente pelo fator climático, tão enraizado na Geomorfologia brasileira.

No setor oeste da área de estudo, foram observadas altimetrias superiores a 170m, tanto a NW do rio Seco quanto a NE do riacho Luís Dias, com presença de morros com superfícies levemente arredondadas, vales e desníveis característicos de uma zona controlada por sua litologia e morfoestrutura, criando uma modelagem típica de áreas onde as falhas geológicas tiveram influência fundamental na configuração do relevo e na rede hidrográfica, conforme verificado no rifteamento que configura o vale do rio Mamanguape (Figuras 4a e 4b).

Ao nordeste da carta de Itapororoca, o rio Santa Cruz, bem como os riachos Luís Dias e Seco são evidências de uma provável ação tectônica ocorrida no local, pois tanto o rio como os dois riachos apresentam sentidos discordantes do padrão de drenagem regional (Figuras 4a e 4b), muito provavelmente condicionados a linhas de falhas. Dentre estas peculiaridades, observa-se a forma como os tributários do rio Seco estão bem encaixados em seus respectivos vales, convergindo para um exutório comum (Figura 4b).

Ao noroeste, a rede fluvial se projeta de maneira peculiar, com elevado gradiente hidráulico atestado pela mudança relativamente brusca na altimetria entre o alto e médio curso. A atuação desse gradiente, nessa parte do terreno, se estabeleceu principalmente no entorno do flanco erodido do episódio Félsico Itapororoca. Essa estrutura é representada por um alto topográfico de bordas suaves e contornos ligeiramente alongados, com altimetria superior a $170 \mathrm{~m}$ em alguns pontos, e com extensão longitudinal de aproximadamente sete quilômetros (Figuras 4a e 4b). Essa morfologia é percebida no modo como afluem os riachos da área em direção ao rio Seco.

Na parte central do rift, onde está delineado o médio curso do rio Mamanguape, o fluxo segue para leste num padrão meandrante irregular. A drenagem fluvial é constituída por uma malha de afluentes pouco en- 
talhados no setor sul desse rio, onde a altimetria não excede $80 \mathrm{~m}$. Já no setor norte, os rios são mais volumosos e conspícuos, ajustados por linhas de falhas na estrutura dos Granitoides (N $\gamma$ i) (Figura 4a), formando um padrão centrípeto que converge em direção ao rio Mamanguape.

Os resultados verificados contribuem, significativamente, com o levantamento de evidências de um possível controle estrutural e tectônico, sucedido no local, conforme observado no padrão da rede de drenagem no setor oeste. Sendo assim, a morfoestrutura da área que é consubstancial na esculturação do relevo, possivelmente, está atrelada a uma morfotectônica conspícua (Figura 2), conforme descrevem Brito Neves et al. (2004), e comprovada através das inúmeras falhas tectônicas verificadas na área (Figura 4a).

No setor central da área de estudo, a imagem Shuttle Radar Topographic Mission (SRTM) e a carta hipsométrica (Figuras 4a e 4b) possibilitaram um entendimento pormenorizado da área, mostrando duas características peculiares principais: o acentuado desnível altimétrico com os tabuleiros localizados ao norte do gráben, com altitudes de até $200 \mathrm{~m}$ e os localizados ao sul, com altitudes máximas de $80 \mathrm{~m}$, perfazendo, portanto, um desnível altimétrico de $120 \mathrm{~m}$ entre os dois tabuleiros que confinam o gráben e que possuem a mesma litologia sedimentar.

A carta clinográfica (Figura 4c) mostra, com grande nitidez, os limites norte e sul do gráben, onde se observam declividades superiores nas vertentes localizadas ao norte, variando com maior frequência valores entre $47 \%$ e $100 \%$, além de exibir com bastante clareza os elevados entalhamentos formados pelos rios Tinto e Jacaré (Figura 4c e Figura 5), cujas vertentes alcançam até $100 \%\left(45^{\circ}\right)$ de declividade. Esses dois rios apresentam-se fortemente encaixados em seus respectivos vales, apontando intenso recuo de suas cabeceiras de drenagem, atestado pelas elevadas declividades e pelas cicatrizes erosivas encontradas.

Os rios Tinto e Jacaré vêm exercendo seu papel de modelador do relevo com extrema "competência", pois estão entalhando, de maneira conspícua, as rochas sedimentares mal consolidadas da Formação Barreiras, produzindo vales estreitos e profundos (Figura 4b). Por serem os principais rios do setor norte que esculpem a Formação Barreiras, formando grandes anfiteatros erosivos, podem ser considerados os grandes fornecedores de sedimentos para o interior do gráben do rio Mamanguape. 


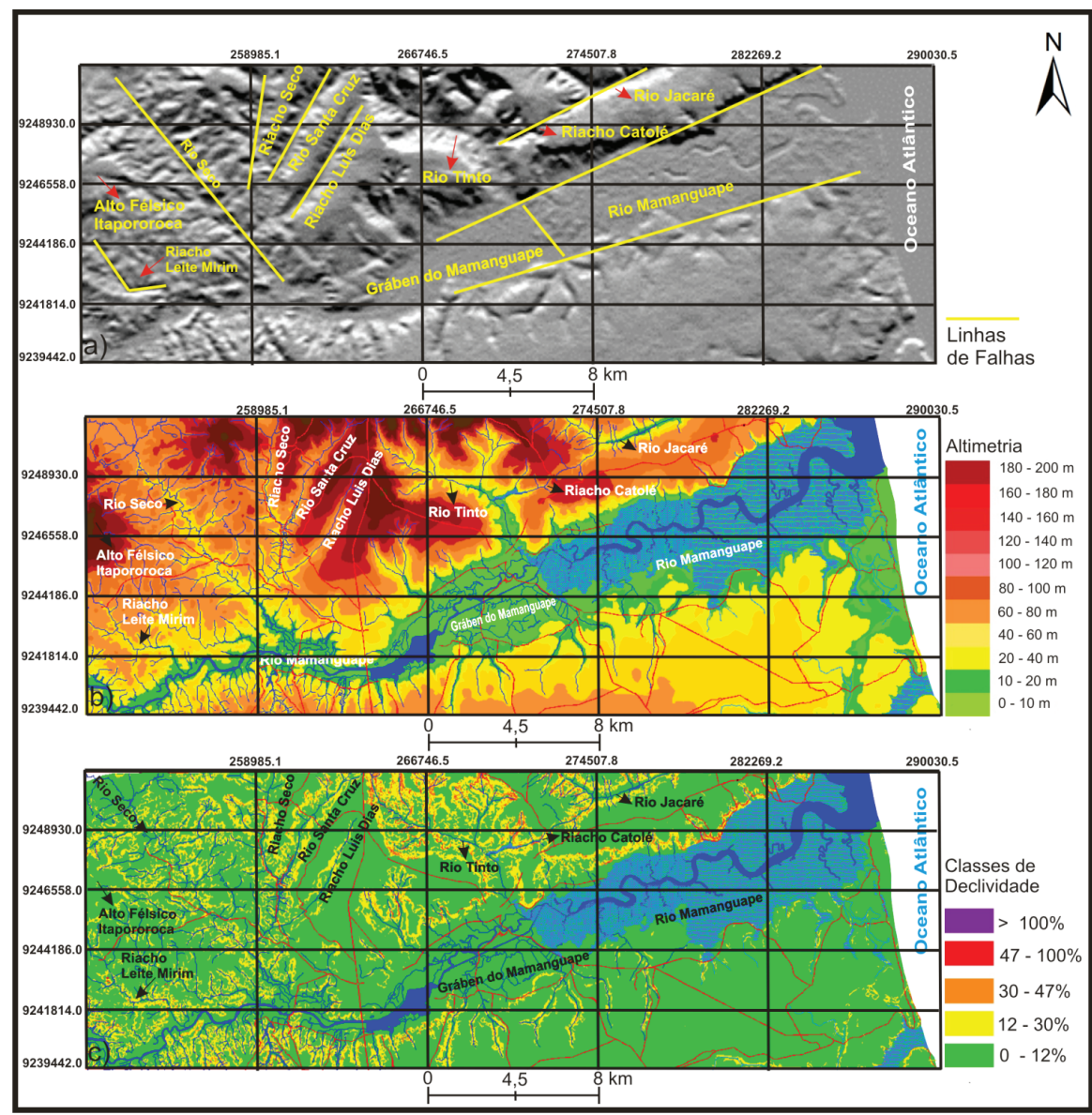

Figura 4 - a) Imagem SRTM; b) Carta hipsométrica; c) Carta clinográfica. Mapas temáticos da área de estudo.

Na foz do rio Tinto, os sedimentos carreados são depositados colmatando a planície fluviomarinha e truncando de maneira retilínea e brusca, na direção NW-SE, o manguezal do rio Mamanguape. Essa retiliniedade corrobora um controle estrutural, tanto da deposição sedimentar como do limite interior do manguezal, que aparece seccionado também na direção NW-SE (Figuras 4a, 4b e 4c). 
O rio Jacaré, localizado no setor centro-leste da área de estudo, entalha fortemente o Tabuleiro Litorâneo, formando um vale fortemente encaixado, retilíneo, paralelo ao rio Gramame e paralelo à linha de falha normal que confina o gráben ao norte. Essas características morfoestruturais e morfológicas sugerem de forma conspícua que esse rio está ajustado a uma linha de falha de mesma direção das falhas que confinam o gráben do rio Mamanguape. As declividades de suas vertentes são superiores a $100 \%\left(45^{\circ}\right)$, o que atesta uma forte incisão erosiva atual colaborando para que esse rio esteja ajustado a uma linha de falha (Figura 4c). Na sua cabeceira principal, verificam-se extensas cicatrizes erosivas associadas às elevadas declividades $\left(>45^{\circ}\right)$, o que fortalece seu acelerado recuo. Esse processo poderá acarretar, num futuro próximo, a captura de drenagem na cabeceira do riacho Catolé, que atualmente dista a apenas 120 m (Figura 4c).

$\mathrm{O}$ rio Mamanguape, em virtude da diferença altimétrica entre os tabuleiros que o confinam (Figura 4b), apresenta uma rede de drenagem extremamente assimétrica, com os rios oriundos dos tabuleiros localizados ao norte mais avantajados, entalhados e com recuos de cabeceiras bastante expressivos, formando vertentes com declividades muito mais superiores que os rios oriundos dos tabuleiros localizados ao sul do gráben (Figura 4c).

Essa acentuada diferença entre os Tabuleiros Litorâneos que confinam o gráben corrobora a ideia de reativações pós-cretácicas na área, visto que as diferenças altimétricas, de declividades, rugosidade do relevo, e a assimetria da rede de drenagem atual não podem ser explicadas apenas pelo fator climático, pois toda a área se encontra sob o mesmo tipo de clima (Tropical Úmido) e com pluviosidade similar (1.800 mm/ano), com a mesma litologia sedimentar (Formação Barreiras), o que impossibilitaria a discrepância morfológica verificada.

No setor leste da área de estudo, é verificada a maior largura do gráben, com aproximadamente 5,12 km de extensão $\mathrm{N}-\mathrm{S}$. Também nessa porção são verificadas cotas altimétricas entres os tabuleiros das porções sul e norte, perfazendo uma diferença de $43 \mathrm{~m}$, menor que a verificada na sua porção central, mas ainda com consideráveis discrepâncias.

Observa-se, também, um maior entalhamento dos vales fluviais com declividades muito superiores aos vales encontrados no setor sul (Figura 4c). As declividades encontradas nas vertentes da porção norte 
do gráben são superiores às das vertentes da porção sul, com a presença bastante nítida de shoulders, facetas triangulares e escarpas de falhas normais verificadas através da imagem SRTM e comprovadas em campo. Estas são características morfológicas relevantes de prováveis atividades neotectônicas.

A elaboração do Modelo Digital de Elevação (MDE) permitiu a visualização detalhada das discrepâncias altimétricas e das peculiaridades morfológicas dos compartimentos (sedimentar e embasamento cristalino) onde se configuram sub-bacias hidrográficas completamente distintas nas suas morfologias, no grau de entalhamento e nas dimensões (Figura 5).
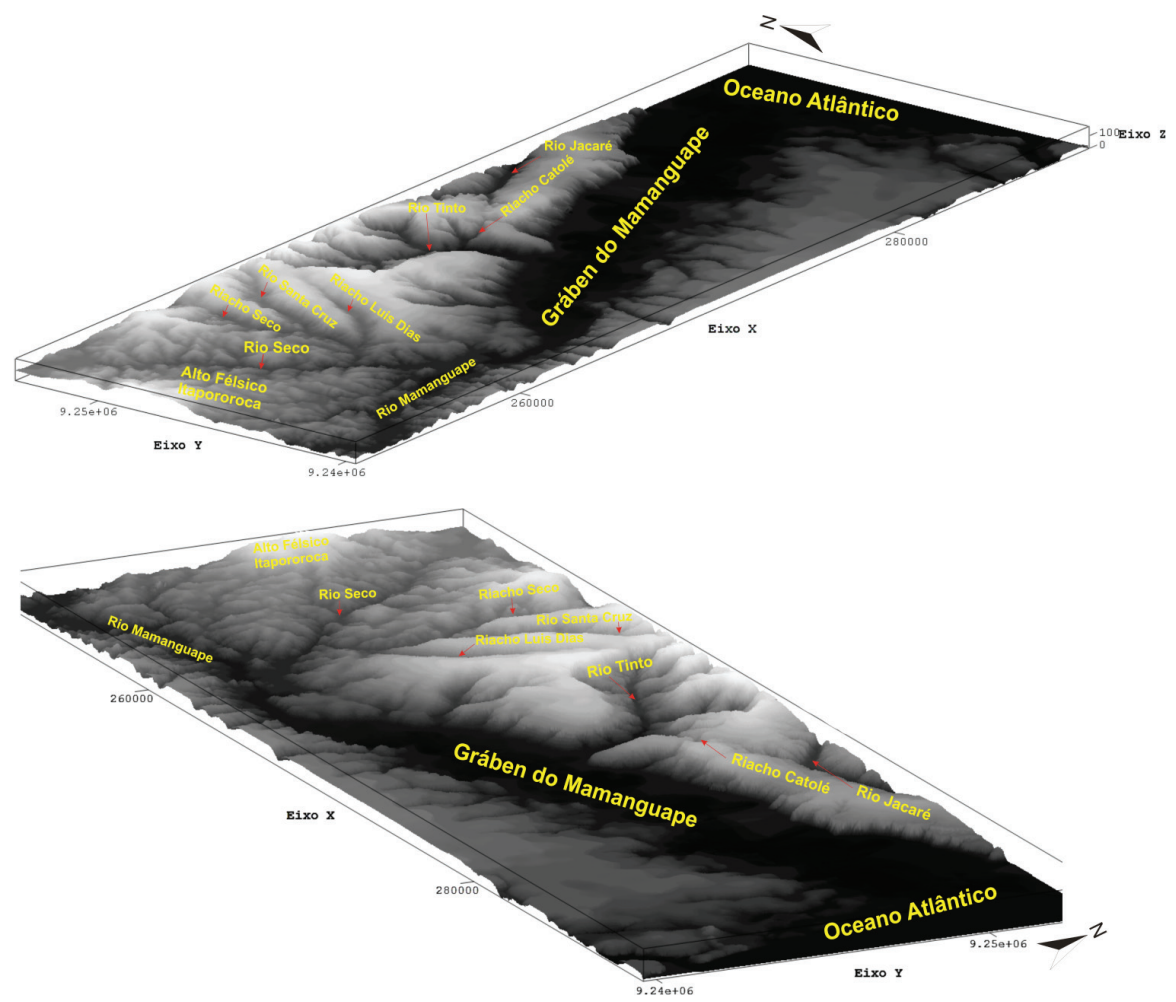

Figura 5- MDE's (Modelos Digitais de Elevação) da área de estudo.

A morfologia das drenagens observadas através do MDE permitiu analisar com maior grau de nitidez o processo de dissecação ocorrido en- 
tre os principais afluentes do rio Mamanguape; assim, as sub-bacias do rio Seco e do rio Tinto são as mais expressivas. A dissecação característica de cada rio provém do substrato que compõe os seus cursos, uma vez que o primeiro rio está inserido num ambiente composto pelo embasamento cristalino, portanto, com menor grau de entalhamento em razão da resistência litológica, e o segundo, em terreno sedimentar composto pela Formação Barreiras.

Com esse mapeamento de detalhe, esta pesquisa evidencia, por meio dos resultados alcançados, que a área apresenta sua morfologia fortemente condicionada ao fator morfoestrutural e morfotectônico, pois a morfologia do relevo verificada não pode ser explicada apenas pelos agentes exógenos. Dessa forma, os estudos realizados no passado sem a ótica do controle morfoestrutural unido à tectônica, sobre o relevo no Brasil, devem ser revistos, em especial, os trabalhos geomorfológicos realizados na borda oriental do Nordeste brasileiro, cujo controle morfoestrutural e morfotectônico é bastante conspícuo e relevante devido ao constante afastamento da América do Sul em relação ao continente africano.

\section{Considerações finais}

A interpretação das cartas temáticas e do MDE possibilitou a constatação de inúmeras evidências de condicionantes morfoestruturais e, muito provavelmente, estruturas morfotectônicas recentes na área de estudo. Dentre elas, as principais são:

\section{Setor oeste:}

O rio Santa Cruz e os riachos Luís Dias e Seco apresentam sentidos discordantes do padrão de drenagem regional, ajustados por linhas de falhas na estrutura das rochas granitoides (N $\gamma \mathrm{i})$;

1. A presença de morros com superfícies levemente arredondadas a NW e vales encaixados, cujas cabeceiras se encontram na Formação Barreiras com sentido NE-SW, totalmente discrepantes quanto ao padrão regional das drenagens;

2. Um elevado gradiente hidráulico na porção NW da área, estabelecido principalmente no entorno do Alto Félsico Itapororoca (Ki); 
3. A presença de rios e riachos centrípetos mais volumosos e acentuados ao norte (encaixados nas falhas) e menos avantajados ao sul, convergindo em direção ao rio Mamanguape.

\section{Setor central:}

1. Um acentuado desnível altimétrico com os tabuleiros localizados na porção norte do gráben, possuindo altitudes de até $200 \mathrm{~m}$;

2. Os rios Tinto e Jacaré apresentam vertentes com declividade superior a 100\% (Figura 4c), sendo estes dois rios fortemente encaixados em seus respectivos vales;

3. Um processo acelerado de recuo de cabeceira do rio Jacaré, atestado pelas vertentes cujas declividades são superiores a $100 \%$ em muitos trechos (Figura 4c), indicando a possibilidade de, num futuro próximo, ocorrer uma captura de drenagem na cabeceira do riacho Catolé, que atualmente dista a apenas $120 \mathrm{~m}$;

4. Uma rede de drenagem extremamente assimétrica. Os rios oriundos dos tabuleiros ao norte são mais avantajados, entalhados, e com recuos de cabeceiras bastante expressivos, formando vertentes com declividades muito mais superiores que os rios localizados nos tabuleiros ao sul do gráben;

5. A presença de estrutura tectônica que trunca de maneira retilínea e fortemente o setor oeste do manguezal no sentido NW-SE, ocasionando uma forte colmatagem a montante.

\section{Setor leste:}

1. A porção da área de estudo apresenta a maior largura do gráben com aproximadamente 5,12 km de extensão N-S;

2. Uma discrepância altimétrica entre os tabuleiros localizados nas porções sul e norte, perfazendo uma diferença de $43 \mathrm{~m}$;

3. A presença de shoulders, facetas triangulares e escarpa de falha normal na porção norte do gráben, evidenciando características morfológicas de atividades neotectônicas. 


\section{Referências}

BRITO NEVES, B. B.; RICCOMINI, C.; FERNANDES, T. M. G.; SANTANA, L. G. O sistema tafrogênico terciário do saliente nordestino na Paraíba: um legado proterozoico. Revista Brasileira de Geociências, v. 34, n. 1, p. 127-134, 2004.

BRITO NEVES, B. B.; MANTOVANI, M. S. M.; MORAES, C. F.; SÍGOLO, J. B. As anomalias geológicas e geofísicas localizadas ao norte de Itapororoca (PB), Folha Guarabira, Revista Brasileira de Geociências, v. 38, n. 1, p. 1-23, 2008.

CPRM. Serviço Geológico do Brasil. Projeto Cadastro de Fontes de Abastecimento por Água Subterrânea: Estado da Paraíba. Recife: CPRM/Prodeem, 10p. 2005.

FEITOSA, E. C.; FEITOSA, F. A. C.; LIRA, H. M. P. Relações estratigráficas e estruturais entre a Bacia Potiguar e a Bacia Costeira (PE/PB) - uma hipótese de trabalho. In: CONGRESSO BRASILEIRO DE ÁGUAS SUBTERRÂNEAS, 12. 2002. Florianópolis, SC. Anais..., Florianópolis: ABAS, v. 1, 2002.

FURRIER, M.; ARAÚJO, M. E.; MENESES, L. F. Geomorfologia e tectônica da Formação Barreiras no estado da Paraíba. Geologia USP-Série Científica, v. 6, n. 2, p. 61-70, 2006a.

. Geomorfologia e tectônica dos tabuleiros litorâneos no norte do estado da Paraíba. In: SIMPÓSIO NACIONAL DE GEOMORFOLOGIA, 6/REGIONAL CONFERENCEON GEOMORPHOLOGY. Anais..., Goiânia: UGB, v. 1, p. 1-9, $2006 b$.

HERZ, R.; DE BIASI, M. Critérios e legendas para macrozoneamento costeiro. Ministério da Marinha/Comissão Interministerial para Recursos do Mar. Brasília: MM, 1989. 138p.

PENTEADO, M. M. Fundamentos de Geomorfologia. Rio de Janeiro: FIBGE, 1974. $141 \mathrm{p}$.

SANTOS, E. J.; NUTMAN, A. P.; BRITO NEVES, B. B. Idades shrimp U-Pb do Complexo Sertânia: implicações sobre a evolução tectônica da Zona Transversal, Província Borborema. Revista do Instituto de Geociências-USP, v. 4, n. 1, p. 1-12, 2004.

SANTOS, E. J.; FERREIRA, C. A.; SILVA, Jr. J. M. F. 2002: Geologia e Recursos Minerais do Estado da Paraíba. Texto Explicativo dos Mapas Geológico e de Recursos Minerais da Paraíba, 1/500 000. Recife: CPRM, 2002. 142p.

Max Furrier - Possui Graduação em Geografia pela Universidade de São Paulo, Mestrado e Doutorado em Geografia pela mesma Universidade. Atualmente é professor de Geociências da Universidade Federal da Paraíba.

Wesley Ramos Nóbrega - Possui Graduação em Geografia pela Universidade Federal da Paraíba. É graduando do Curso Superior de Tecnologia em Geoprocessamento pelo Instituto Federal de Educação, Ciência e Tecnologia da Paraíba e bolsista do programa Ciências sem Fronteiras. 
Alexandre dos Santos Souza - Possui Graduação em Geografia pela Universidade Federal da Paraíba. Atualmente é Mestrando em Geografia pela mesma Universidade.

Recebido para publicação em 19 de dezembro de 2014 Aceito para publicação em 10 de fevereiro de 2015 